\title{
Monoblastic Sarcoma
}

National Cancer Institute

\section{Source}

National Cancer Institute. Monoblastic Sarcoma. NCI Thesaurus. Code C35816.

A less common form of myeloid sarcoma composed of monoblasts. Monoblastic sarcoma may precede or occur simultaneously with acute monoblastic leukemia. (WHO 2001) 